\title{
Program to Determine the Terrain Roughness Index using Path Profile Data Sampled at Different Moving Window Sizes
}

\author{
Simeon Ozuomba \\ Department of Electrical/Electronic \\ and Computer Engineering \\ University of Uyo \\ Akwa Ibom State Nigeria
}

\author{
Henry Johnson Enyenihi \\ Department of Electrical/Electronic \\ Engineering, Akwa lbom State \\ University Mkpat Enin, \\ Akwa Ibom State, Nigeria
}

\author{
Constance Kalu \\ Department of Electrical/Electronic \\ and Computer Engineering \\ University of Uyo \\ Akwa Ibom State Nigeria
}

\begin{abstract}
In this paper development of a program to determine the terrain roughness index using path profile data sampled at different moving window sizes is presented. Relevant mathematical expressions and algorithm to determine terrain roughness index from elevation data captured at different moving window sizes are presented. The desktop program is written in Visual Basic for Application. The program enables users to sample the elevation data at a given window size and then determine the terrain roughness parameters at any other window size that is multiple of the original sampling window size. Sample $58.5523249 \mathrm{Km}$ study path location that started at a latitude of 5.48717 and longitude of 7.04193 and ended at a latitude of 5.82096 and a longitude of 7.45042 was used to demonstrate the effectiveness of the software. Specifically, Geocontext online elevation profile software is used on the study path to capture $\mathrm{N}=512$ path profile data at an initial window size of 3.75 seconds which is equivalent to a distance of $114.5838061 \mathrm{~m}$. The roughness index is computed at four (4) other sampling window sizes of 30 seconds, 1 minute (60 seconds) , 5 minutes (300 seconds) and 10 minutes (600 seconds). Among other things the program showed the window sizes and their corresponding terrain roughness index along with the elevation profile table and graph for each of the sampling window size. The results show that as the widows size increases the total number of sample data points decreases. Also, the largest terrain roughness index value of $52.89 \mathrm{~m}$ is observed with window size of 300 seconds whereas the lowest largest terrain roughness index value of $33.55 \mathrm{~m}$ is observed with window size of 600 seconds. The idea presented in this paper is useful for wireless network designer who relies on terrain roughness value for the determination of the multipath fade depth for detailed link design.
\end{abstract}

\section{Keywords}

Multipath, Fading Depth, Terrain Roughness Index, Elevation Profile, Geographic Reference System, Sampling Window

\section{INTRODUCTION}

Multipath fading is the losses in signal strength which occurs when signals travel through different paths before they reach the receiver $[1,2,3,4,5,6,7]$. The multipath effect will always occur when there is a change in the path of the different components of the signal. As a result of the changes in the signal path, different components of the signal travel through different paths and path lengths before they reach the receiver. In all, at the receiver, the overall signal strength is reduced due to the multipath effect $[8,9,10,11]$.
Notably, the nature of the path elevation profile has been identified as one of the causes of multipath in wireless signal communications systems. Due to the coarse nature of the ground surface signals are reflected at some points as they hit the ground and this ground reflection of signals causes the multipath effect $[12,13,14]$. Consequently, in a bid to account for the impact of terrain roughness on multipath fading, the International Telecommunication Union (ITU) Recommendation ITU-R P.530-17 incorporated terrain roughness index as part of the parameters for computing multipath fade depth [15].

Basically, the terrain roughness index is the standard deviation of elevation values obtained from the elevation data point captured around the signal path $[16,17,18]$. However, the approach presented by ITU-R P.530-17 model for computing the terrain roughness index adopted very large distance between elevation data points used in computing the terrain roughness index. As such, researchers in many cases compute terrain roughness index based on elevation data point with a smaller distance between elevation data points [19].

Furthermore, today, there are available online tools for capturing elevation profile data at a different time or distance resolutions. As such, in his paper, the focus is the development of relevant algorithms for a program that will enable users to determine the terrain roughness index of a given area based on the elevation profile data of the area. In the program, it is assumed that the elevation data is captured by an elevation profile data capturing tool that provides information of the distance and elevation of data points along the signal path. It is also assumed that the tool enables the user to select the time interval or distance interval between consecutive elevation data point it will capture and also the interval is the same between all the elevation data points. While the algorithm is presented here, the program is written in Visual Basic for Application (VBA). The requisite mathematical expressions and algorithms used in the program are presented in the succeeding section. The program enables the user to determine the terrain roughness index at higher resolutions that are multiples of the original resolution used to capture the elevation profile data.

\section{METHODOLOGY}

\subsection{The Theoretical Background On Terrain Roughness Index}

Terrain roughness index can be determined from path profile data with respect to the distance in kilometres and the elevations in meters. Basically, the terrain roughness index $\left(S_{a}\right)$ is the standard deviation of the elevation for the various 
path profile data points considered . Assuming there are $\mathrm{N}$ elevation $\left(E_{n}\right)$ data points in the path profile where $n=$ $1,2, \ldots \mathrm{N}$, then the terrain roughness index $\left(\mathrm{S}_{\mathrm{a}}\right)$ is given as [15];

$$
S_{a}=\sigma=\sqrt[2]{\left(\frac{\sum_{n=1}^{n=N}\left(E_{n}-\overline{\mathrm{E}}\right)^{2}}{N-1}\right)}
$$

Where the average elevation $\overline{\mathrm{E}}$ is given as [15];

$$
\overline{\mathrm{E}}=\frac{\sum_{n=1}^{n=N}\left(E_{n}\right)}{N}
$$

In this study, it is assumed that the path profile data is captured at a given constant value moving window size (for instance, one sample every 10 seconds) such that the distance, $\delta_{\mathrm{w}}$ between sampling point in the given window size, $\mathrm{w}$ is equal. The path length, $d$ which is the distance between the starting point (with $n=1$ ) of the profile data sampling to the last point (with $\mathrm{n}=\mathrm{N}$ ) on the data sampling is given as ;

$$
d=d_{N}-d_{1}=N\left(\delta_{w}\right)
$$

Where $d_{n}$ is the distance from data point 1 to data point $n$, and $\mathrm{d}_{1}=0$. Hence,

$$
d=d_{N}=d_{N}-d_{1}=N\left(\delta_{w}\right)
$$

If the elevation at the required distance point $\mathrm{p}$ is not available where $d_{p}$ denotes the distance at point $p$ and $E_{p}$ denotes the elevation at point $p$, then interpolation of the two nearest profile points to point $\mathrm{d}$ can be used to obtain the elevation, $\mathrm{E}_{\mathrm{p}}$ as follows;

$$
E_{p}=E_{n}+\left[\left(\frac{d_{p}-d_{n}}{d_{(n+1)}-d_{n}}\right)\left(E_{(n+1)}-E_{n}\right)\right]
$$

Where are $E_{n}$ and $E_{(n+1)}$ are the elevations while $d_{n}$ and $d_{(n+1)}$ are the distance of the points nearest to the profile point $\mathrm{p}$ and $\mathrm{d}_{\mathrm{n}} \leq \mathrm{d}_{\mathrm{p}} \leq \mathrm{d}_{(\mathrm{n}+1)}$.

\subsection{The Theoretical Background On The Sampling Window Sizes}

In geographic reference system $1^{\circ}$ (that is , 60 minutes or 3600 seconds ) of latitude is equivalent to a distance of 110 $\mathrm{Km}$. Smaller resolution in seconds and minutes can be used whereby 1 second is equivalent to a distance of $30.56 \mathrm{~m}$. In the elevation data capture software tool, the elevation points are captured at a given constant time unit called the sampling window of size, w. It is assumed that the data sampling mechanism moves at a constant speed along the path and captures elevation data every w time units. Since the speed is constant and the sampling window size (time) is also constant, then the distance from one sample point, $\mathrm{n}$ to the next sample point $\mathrm{n}+1$ is constant and it is denoted as $\delta_{\mathrm{w}}$, where $\mathrm{w}$ represents the sampling window size (time) used. For instance, sampling window size (time) $\mathrm{w}=1$ second means $\delta_{1 \mathrm{sec}}=30.56 \mathrm{~m}$. Other sampling sizes and their corresponding sampling distance sizes can be obtained from the 1 second window size values. For instance $\delta_{30 \mathrm{sec}}=30\left(\delta_{1 \mathrm{sec}}\right)=$ $916.67 \mathrm{~m}$ and $\delta_{1 \mathrm{~min}}=\delta_{60 \mathrm{sec}}=60\left(\delta_{1 \mathrm{sec}}\right)=1833.6 \mathrm{~m}$. In this paper, the second will be used as the reference time unit to relate the distance among different sampling window sizes.

Now, consider a situation where the software tool is used to capture the elevation data at a window size of $w_{1}$ seconds which has corresponding sampling distance of $\delta_{\mathrm{w} 1}$ and then, the roughness index parameter is needed at a different sampling size $\mathrm{w}_{2}$ seconds (where $\mathrm{w}_{2} \geq \mathrm{w}_{1}$ ), then the number (denoted as $\mathrm{K}_{\mathrm{w} 21}$ ) of $\mathrm{w}_{1}$ sample points that will make up one $\mathrm{W}_{2}$ sample point is given as ;

$$
K_{w 21}=\frac{w_{2}}{w_{1}}
$$

Hence,

$$
\delta_{w 2}=\left(K_{w 21}\right) \delta_{w 1}=\left(\frac{w_{2}}{w_{1}}\right) \delta_{w 1}
$$

For instance, if $\mathrm{w}_{1}$ is 5 seconds such that the $\delta_{\mathrm{w} 1}=\delta_{5 \mathrm{sec}}=$ $5(30.56)=152.8 \mathrm{~m}$ and if the roughness index is required at the sampling rate of $\mathrm{w}_{1}=30$ seconds then, $\mathrm{K}_{\mathrm{w} 21}=\frac{\mathrm{w}_{2}}{\mathrm{w}_{1}}=$ $\frac{30}{5}=6 \quad$ and $\quad$ so $\quad \delta_{\mathrm{w} 2}=\delta_{30 \mathrm{sec}}=6(152.8)=916.8$. In practice, it is advised that the data capturing windows size be such that the required window sizes for computing roughness index are multiples of the original capturing windows size otherwise the data point will point at the location where there is no elevation data. In such case, interpolation may be used as specified in Equation 5. However, such occasion should be avoided. The total number of data points, $\mathrm{N}_{2}$ when the data is resampled at the window size of $\mathrm{w}_{2}$ from its original $\mathrm{N}_{1}$ sampling at the window size of $\mathrm{w}_{1}$ is given as ;

$$
N_{2}=\left\lfloor 1+\left(\frac{N_{1}-1}{K_{w 21}}\right)\right\rfloor
$$

Where $\lfloor x\rfloor$ means integer part of $\mathrm{x}$.

\section{THE ALGORITHM FOR \\ DETERMINATION OF THE TERRAIN ROUGHNESS INDEX USING PATH PROFILE DATA SAMPLED AT DIFFERENT MOVING WINDOW SIZES}

The algorithm for the algorithm for determination of the terrain roughness index using path profile data sampled at different moving window sizes are given in following submodules:

Module 1: Read in the $\mathrm{N}$ original data points captured by the path profile data capture software toolset at window size $\mathrm{w}_{0}$

Module 2: Generate data points at another window size , $\mathrm{w}_{\mathrm{x}}$ based on the $\mathrm{N}$ original data points captured by the path profile data capture software tool

Module 3: Compute the average elevation for the data points at another window size, $\mathrm{w}_{\mathrm{X}}$

Module 4: Compute the roughness index for the data points at another window size, $\mathrm{w}_{\mathrm{x}}$

The detailed algorithm is as follows:

Module 1: Read in the $\mathrm{N}$ original data points captured by the path profile data capture software toolset at window size $\mathrm{w}_{0}$ Step 1: INPUT the data capture window size
,$w_{0}$, the number of data points,$N$

Step 2: $w=w_{0}$

Step 3: FOR $n=1$ to $\mathbf{N}$ step 1 
Step 4: READ the data point distance $\delta_{\left(\mathbf{w}_{0}, n\right)}$ and the data point elevation $E_{\left(\mathbf{w}_{0}, n\right)}$

Step 4: NEXT n

Step 5 CALL Module 2

Step 6: END

Module 2: Generate data points at another window size, $\mathrm{w}_{\mathrm{x}}$ based on the $\mathrm{N}$ original data points captured by the path profile data capture software tool

Step 1: $x=1$

Step 2: INPUT the required roughness index sampling window size, $\mathbf{w}_{\mathrm{x}}$

Step 3: COMPUTE $K_{w_{x} w_{0}}=\frac{w_{x}}{w_{0}}$

Step 4: INITIALISE $\mathbf{i}=1$ // counter for data points in sampling window size, $w_{x}$

Step 5: FOR $\mathbf{n}=1$ to $\mathbf{N}$ STEP $K_{w_{x} w_{0}}$

Step 6: READ the data point distance $\delta_{\left(\mathbf{w}_{0}, n\right)}$ and the data point elevation $E_{\left(\mathbf{w}_{0}, n\right)}$

Step 7: $\delta_{\left(\mathbf{w}_{\mathbf{x}}, i\right)}=\delta_{\left(\mathbf{w}_{\mathbf{0}}, n\right)}$

Step 8: $E_{\left(\mathbf{w}_{\mathbf{x}}, i\right)}=E_{\left(\mathbf{w}_{\mathbf{0}}, n\right)}$

Step 9: NEXT n

Step 10: $\quad N(x)=i / / N(x)$ is the total number of sampled data points obtained when data is sampled at window size, $w_{x}$

Step 11: IF ( $w_{x}$ is the last window size to be considered ) THEN

Step 11.1:

$X_{N}=\mathbf{x}$

Step 11.2:

CALL Module 3

Step 11.3:

ELSE

Step 11.4:

$\mathbf{x}=\mathbf{x}+\mathbf{1}$

Step 11.5:

GOTO Step 2

Step 11.6:

\section{ENDIF}

Step 12: RETURN

// Compute the roughness index, Sa for the Xn different window sizes, $w_{x}$ where $\mathrm{x}=$ $1,2, \ldots, \mathrm{Xn}$

Module 3: Compute the average elevation for the data points at another window size, $w_{x}$

Step 1: $\quad x=1$

Step 2: Sum $_{x}=0$ // Initialise Sum Su $_{x}$ to

Step 3: FOR $\mathrm{i}=1$ to $X_{N}$ STEP 1
Step 4: Sum $_{\boldsymbol{x}}=\boldsymbol{S u m}_{\boldsymbol{x}}+E_{\left(\mathrm{w}_{\mathrm{x}}, i\right)}$

Step 5: NEXT i

Step 6: $\quad A V G_{x}=\frac{\operatorname{Sum}_{x}}{\mathrm{~N}(\mathrm{x})}$

Step 7: $\quad$ IF $\left(\boldsymbol{x} \geq X_{N}\right)$ THEN

Step 7:1

CALL Module 4

Step 7.2:

ELSE

Step 7.3:

$\mathbf{x}=\mathbf{x}+\mathbf{1}$

Step 7.4:

GOTO Step 2

Step 7.5:

ENDIF

Step 8: RETURN

Module 4: Compute the roughness index for the data points at another window size, $\mathrm{w}_{\mathrm{x}}$

Step 1: $\quad x=1$

Step 2: $\operatorname{SumSq}_{x}=0$ // Initialise sum of squared error, $S u m S q_{x}$ to 0

Step 3: FOR $\mathrm{i}=1$ to $X_{N}$ STEP 1

Step 4: $\operatorname{SumSq}_{x}=\operatorname{SumSq_{x}}+\left(E_{\left(\mathrm{w}_{\mathrm{x}}, i\right)}\right.$ $\left.\boldsymbol{A V} \boldsymbol{G}_{\boldsymbol{x}}\right)^{2}$

Step 5: NEXT i

Step 6: $\quad S_{a x}=\left(\sqrt[2]{\frac{S u m S q_{x}}{(\mathrm{~N}(\mathrm{x})-1)}}\right)$

Step 7: $\quad$ IF $\left(x \geq X_{N}\right)$ THEN

Step 8:

GOTO Step 9

Step 8.2:

ELSE

Step 8.3:

$\mathbf{x}=\mathbf{x}+1$

Step 8.4:

GOTO Step 2

Step 8.5:

ENDIF

\section{Step 9 RETURN}

In the flowchart it is assumed that the window sizes, $\mathrm{w}_{\mathrm{x}}$ are multiples of the original sampling window size $\mathrm{w}_{0}$. In this case no interpolation is required.

A program is written in Visual Basic for Application to automate the computation of the relevant parameters once the required input data are keyed in.

Particularly, the following 4 sets of input data are required for the program ;

i. $\mathrm{X}_{N}$, the number of sampling window sizes to be used

ii. Window sizes $w_{0}, w_{1}, w_{2}, \ldots w_{\mathrm{X}_{N}}$

iii. $\mathrm{N}$, the number of data points for the initial window size $w_{0}$

iv. For $\mathrm{n}=1$ to $\mathrm{N}$ input data point distance, $\delta_{\left(w_{0}, n\right)}$ and data point elevation $E_{\left(w_{0}, n\right)}$ of the initial window size, $w_{0}$

Among other things, the program output includes the following ; 
i. Sampling Window Size Name, $w_{\mathrm{x}}$ where $\mathrm{x}=$ $0,1,2, \ldots X_{\mathrm{N}}$

ii. Sampling Window Size in Time Unit (seconds)

iii. Sampling Window Size in Meters

iv. $\quad K_{w_{x} w_{0}}=\frac{w_{x}}{w_{0}}:$ the number of units of Window Size $w_{0}$ that make up 1 Window Size $w_{x}$

v. $\quad N_{\mathrm{x}}$ : Total number of sampled data points for Window Size $w_{\mathrm{x}}$

vi. For $\mathrm{n}=1$ to $N_{\mathrm{x}}$ output data point distance, $\delta_{\left(w_{0}, n\right)}$ and data point elevation $E_{\left(w_{0}, n\right)}$ of window size $w_{\mathrm{x}}$

vii. Sumx : Sum of elevations for Window Size $w_{\mathrm{x}}$

viii. AVGx : Average of elevations for Window Size $w_{\mathrm{x}}$

ix. SumSqx: Sum of square error of elevations for Window Size $w_{x}$ x. Sax : Terrain roughness index for Window Size $\mathrm{w}_{\mathrm{X}}$

\section{NUMERICAL EXAMPLE}

The $58.5523249 \mathrm{Km}$ study path location started at a latitude of 5.48717 and a longitude of 7.04193 and ended at a latitude of 5.82096 and a longitude of 7.45042. Geocontext online elevation profile software is used on the study path to capture $\mathrm{N}=512$ path profile data at an initial window size $\mathrm{w}_{0}$ of 3.75 seconds which is equivalent to a distance of $\delta_{(3.75 \mathrm{sec})}=114.5838061 \mathrm{~m}$. Meanwhile the roughness index is required at the following four (4) sampling window sizes; 30 seconds, 1 minute (60 seconds) , 5 minutes (300 seconds) and 10 minute s(600 seconds). Accordingly, the program presented in this paper is used to compute the roughness index for the each of the given 4 different sampling window sizes

A portion of the originally sampled data using window size , $\mathrm{w}_{0}$ of 3.75 seconds is shown in Table 1 while the elevation profile of the complete path is shown in Figure 1.

Table 1 Portion of the originally sampled data using window size, $w_{0}$ of 3.75 seconds

\begin{tabular}{|c|c|c|c|c|}
\hline Data Point Number, $n$ & Distance $(\mathrm{m})$ & Elevation (m) & Latitude & Longitude \\
\hline 1 & 0 & 73 & 5.48717 & 7.04193 \\
\hline 2 & 114.583806 & 73.28502 & 5.48782349 & 7.04272894 \\
\hline 3 & 229.167612 & 73.11905 & 5.48847697 & 7.04352788 \\
\hline 4 & 343.751418 & 72.83546 & 5.48913045 & 7.04432682 \\
\hline 5 & 458.335224 & 71.80804 & 5.48978394 & 7.04512576 \\
\hline 6 & 572.91903 & 72.02904 & 5.49043742 & 7.04592471 \\
\hline 7 & 687.502836 & 72.99104 & 5.4910909 & 7.04672365 \\
\hline 8 & 802.086642 & 71.78662 & 5.49174438 & 7.0475226 \\
\hline 9 & 916.670449 & 73.62459 & 5.49239785 & 7.04832155 \\
\hline 10 & 1031.25425 & 73.39307 & 5.49305133 & 7.0491205 \\
\hline 503 & 57521.0706 & 123.5818 & 5.81508361 & 7.44322134 \\
\hline 504 & 57635.6545 & 123.7228 & 5.81573655 & 7.44402119 \\
\hline 505 & 57750.2383 & 123.0307 & 5.81638948 & 7.44482103 \\
\hline 506 & 57864.8221 & 121.9574 & 5.81704242 & 7.44562088 \\
\hline 507 & 57979.4059 & 123.0356 & 5.81769535 & 7.44642073 \\
\hline 508 & 58093.9897 & 121.6979 & 5.81834828 & 7.44722058 \\
\hline 509 & 58208.5735 & 119.3775 & 5.81900121 & 7.44802043 \\
\hline 510 & 58323.1573 & 116.0922 & 5.81965414 & 7.44882029 \\
\hline 511 & 58437.7411 & 114.2163 & 5.82030707 & 7.44962014 \\
\hline 512 & 58552.3249 & 109.8918 & 5.82096 & 7.45042 \\
\hline
\end{tabular}




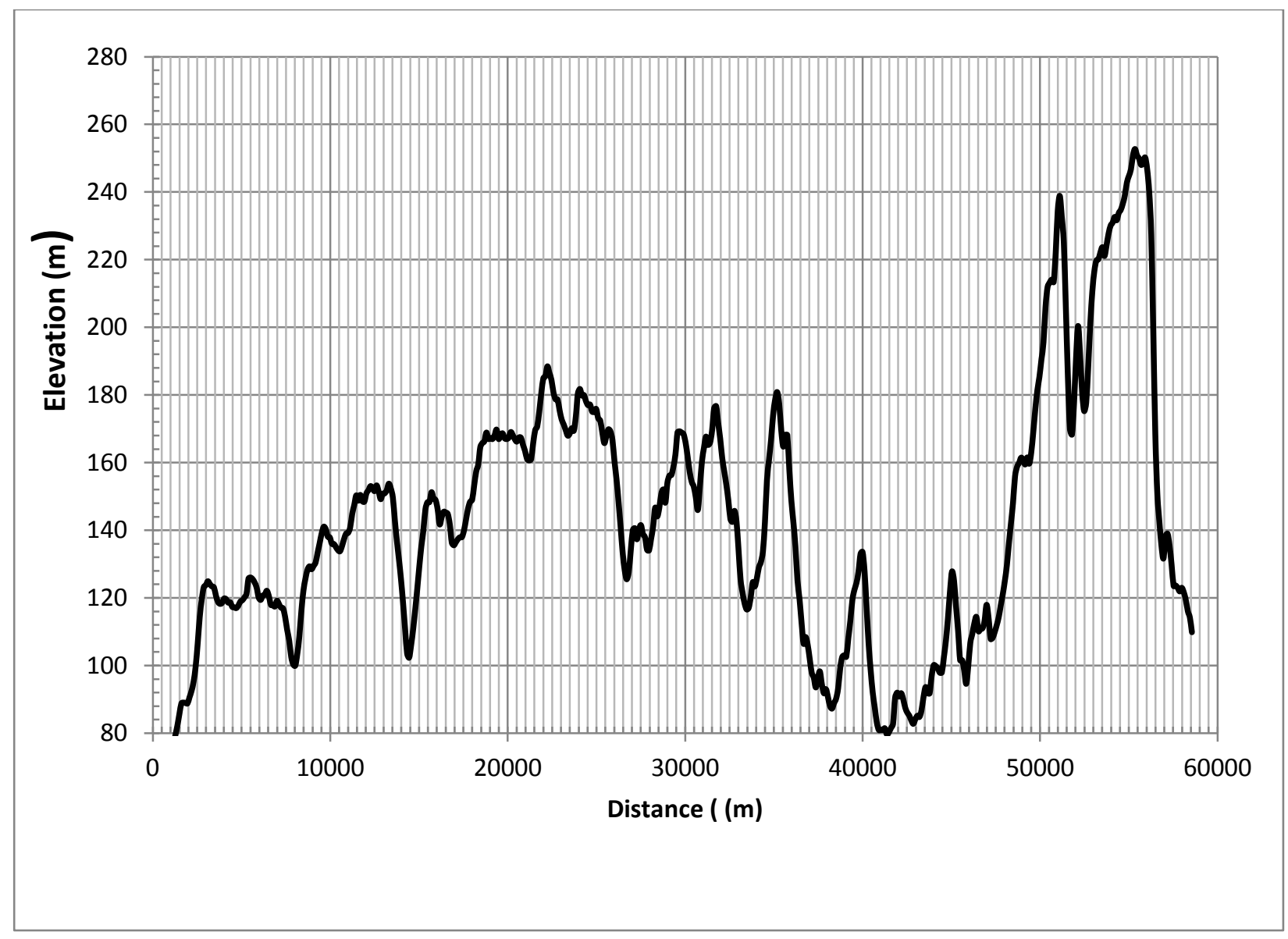

Figure 1 The elevation profile of the complete path

The results in Table 2 show the output of the window sizes and the corresponding terrain roughness index. The larger the widow size the larger the value of $\mathrm{K}_{\mathrm{w}_{\mathrm{x}} \mathrm{w}_{0}}$ and the smaller is the total number of sample data points . The largest terrain roughness index value of $52.89 \mathrm{~m}$ is observed with a window size of 300 seconds whereas the lowest largest terrain roughness index value of $33.55 \mathrm{~m}$ is observed with a window size of 600 seconds.

The program also displays the elevation profile table and graph for the various sampling window sizes. Table 2 and Figure 2 show the elevation profile table and graph for the sampling window size, $\mathrm{w}_{2}$ of 1 Minute ( 60 seconds). A total

Table 2 The output of the program showing the window sizes and the corresponding terrain roughness index

\begin{tabular}{|c|c|c|c|c|c|c|c|c|}
\hline $\begin{array}{c}\text { Sampling } \\
\text { Window } \\
\text { Size Name }\end{array}$ & $\begin{array}{c}\text { Sampling } \\
\text { Window } \\
\text { Size in } \\
\text { Time Unit } \\
\text { (seconds) }\end{array}$ & $\begin{array}{c}\text { Sampling } \\
\text { Window } \\
\text { Size in } \\
\text { Meters }\end{array}$ & $\begin{array}{c}\text { Total } \\
\text { Number Of } \\
\text { Sample } \\
\text { Data Points } \\
\left(N_{\mathrm{x}}\right)\end{array}$ & $\mathbf{K}_{\mathbf{w}_{\mathbf{x}} \mathrm{w}_{\mathbf{0}}}$ & Sumx & AVGx & SumSqx & Sax \\
\hline w0 & 3.75 & 114.58 & 512 & 1 & 72768.61 & 142.13 & 785007.32 & 39.19 \\
\hline w1 & 30 & 916.67 & 64 & 8 & 9220.89 & 141.86 & 104735.52 & 40.45 \\
\hline w2 & 60 & 1833.34 & 32 & 16 & 4628.01 & 140.24 & 53846.96 & 41.02 \\
\hline w3 & 300 & 9166.70 & 7 & 80 & 1060.41 & 132.55 & 19583.69 & 52.89 \\
\hline w4 & 600 & 18333.41 & 4 & 160 & 611.10 & 122.22 & 4502.30 & 33.55 \\
\hline
\end{tabular}

of 32 data sampling points are captured with sampling

Similarly, Table 23 and Figure 3 show the elevation profile table and graph for the sampling window size , $w_{3}$ of 5 Minutes (300 seconds). A total of 7 data sampling points are captured with sampling window size of 300 seconds. window size of 60 seconds. 
Table 2 The elevation profile of the window size, $w_{2}$ of 1 Minute ( 60 seconds)

\begin{tabular}{|c|c|c|c|c|c|}
\hline $\begin{array}{c}\text { Data } \\
\text { Point } \\
\text { Number } \\
\text { n }\end{array}$ & Distance (m) & $\begin{array}{l}\text { Elevation }(\mathrm{m}) \text { For } \\
\text { Window Size } 1 \\
\text { Minute (60 } \\
\text { Seconds) }\end{array}$ & $\begin{array}{l}\text { Data Point } \\
\text { Number, } n\end{array}$ & Distance (m) & $\begin{array}{c}\text { Elevation }(m) \text { For Window Size } 1 \\
\text { Minute (60 Seconds) }\end{array}$ \\
\hline 1 & 0 & 73.00 & 17 & 29333.45 & 158.86 \\
\hline 2 & 1833.34 & 89.00 & 18 & 31166.80 & 167.74 \\
\hline 3 & 3666.68 & 118.83 & 19 & 33000.14 & 134.40 \\
\hline 4 & 5500.02 & 126.07 & 20 & 34833.48 & 166.77 \\
\hline 5 & 7333.36 & 116.95 & 21 & 36666.82 & 106.52 \\
\hline 6 & 9166.70 & 130.52 & 22 & 38500.16 & 90.25 \\
\hline 7 & 11000.05 & 139.27 & 23 & 40333.50 & 106.39 \\
\hline 8 & 12833.39 & 149.23 & 24 & 42166.84 & 91.88 \\
\hline 9 & 14666.73 & 110.91 & 25 & 44000.18 & 100.14 \\
\hline 10 & 16500.07 & 145.31 & 26 & 45833.52 & 94.63 \\
\hline 11 & 18333.41 & 159.51 & 27 & 47666.86 & 114.44 \\
\hline 12 & 20166.75 & 169.09 & 28 & 49500.20 & 163.16 \\
\hline 13 & 22000.09 & 184.97 & 29 & 51333.55 & 225.02 \\
\hline 14 & 23833.43 & 173.68 & 30 & 53166.89 & 219.82 \\
\hline 15 & 25666.77 & 169.87 & 31 & 55000.23 & 244.79 \\
\hline 16 & 27500.11 & 141.56 & 32 & 56833.57 & 135.54 \\
\hline
\end{tabular}

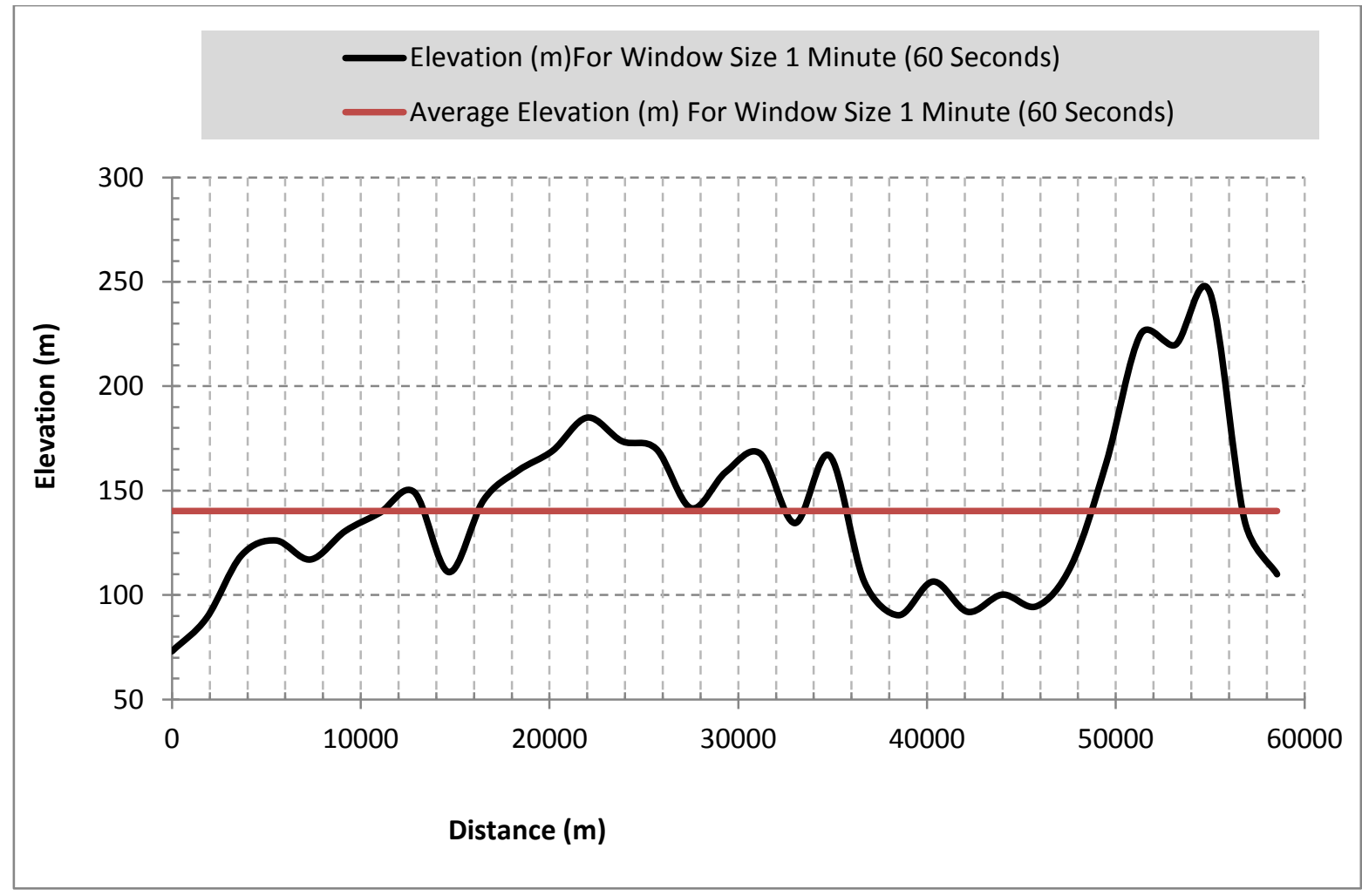

Figure 2 The elevation profile of the window size, $w_{2}$ of 1 Minute ( 60 seconds) 
Table 3 The elevation profile of the window size, $w_{3}$ of 5 Minutes ( 300 seconds)

\begin{tabular}{|c|c|c|}
\hline Data Point Number, $\mathrm{n}$ & Distance $(\mathrm{m})$ & $\begin{array}{c}\text { Elevation (m) For Window Size 5 Minutes (300 } \\
\text { Seconds) }\end{array}$ \\
\hline 1 & 0 & 73 \\
\hline 2 & 9166.704 & 130.5188 \\
\hline 3 & 18333.41 & 159.505 \\
\hline 4 & 27500.11 & 141.5607 \\
\hline 5 & 36666.82 & 106.5168 \\
\hline 6 & 45833.52 & 94.63456 \\
\hline 7 & 55000.23 & 244.7859 \\
\hline
\end{tabular}

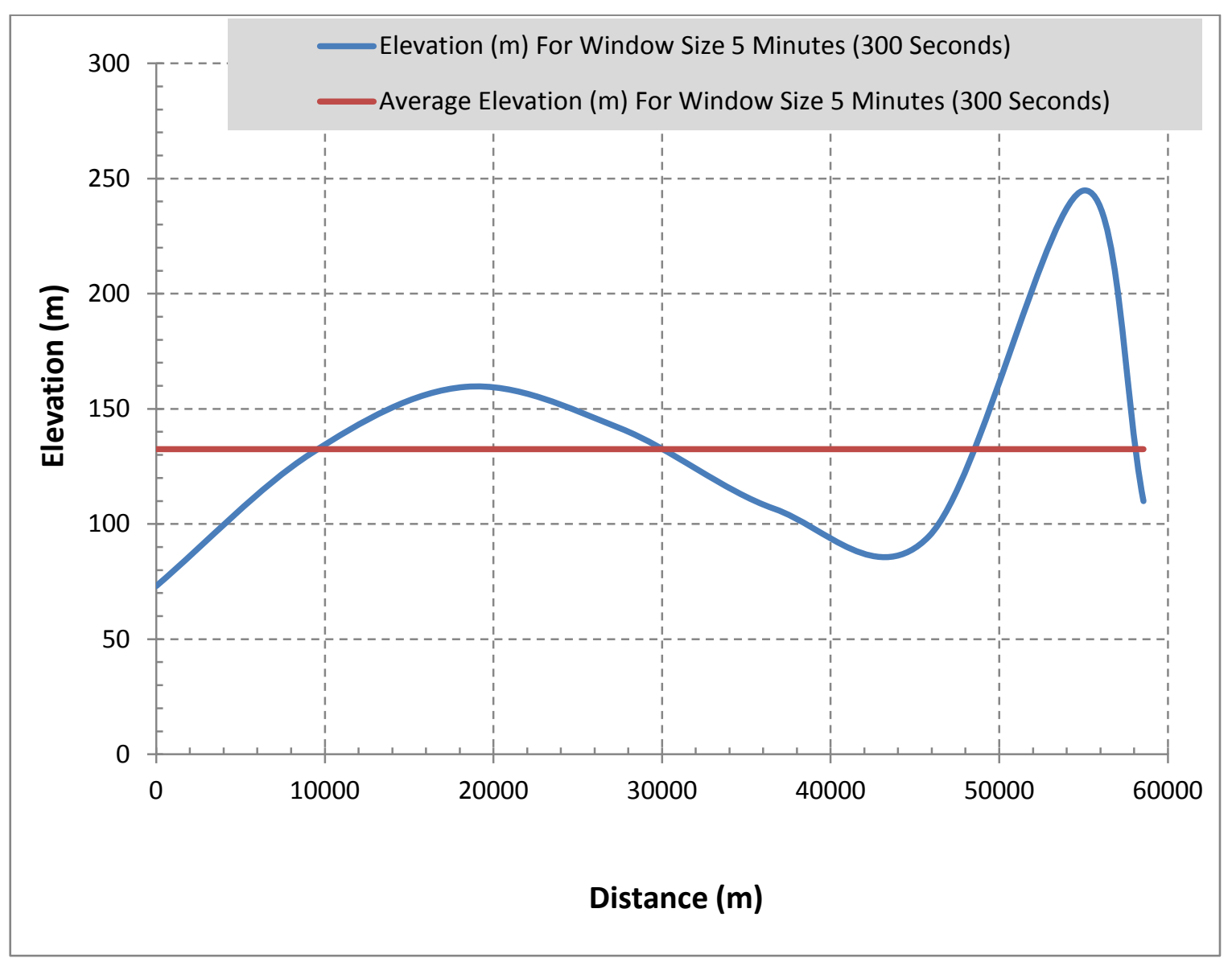

Figure 3 The elevation profile of the window size, $w_{3}$ of 5 Minutes (300 seconds)

\section{CONCLUSION}

Mathematical expressions and algorithm along with a program to determine terrain roughness index from elevation data captured at different moving window sizes are presented. The elevation data profile is captured using an online elevation profile data software which captures elevation data at a given regular time or distance interval (window sizes). The program enables users to sample the elevation data at a given window size and then determine the terrain roughness parameters at any given window size that is multiple of the original sampling window size. The program is written in Visual Basic for Application (VBA) and it is a desktop application. Sample path profile is used to demonstrate the effectiveness of the program to determine the essential terrain roughness parameters for different sampling window sizes.

\section{REFERENCES}

[1] Ellis, T., \& Weiss, S. (2018, April). Propagation Prediction for Rail Communications in Urbanized Areas. In 2018 Joint Rail Conference (pp. V001T03A006V001T03A006). American Society of Mechanical Engineers.

[2] Reis, S., Pesch, D., Wenning, B. L., \& Kuhn, M. (2018, April). Empirical path loss model for $2.4 \mathrm{GHz}$ IEEE 802.15. 4 wireless networks in compact cars. In Wireless 
Communications and Networking Conference (WCNC), 2018 IEEE (pp. 1-6). IEEE.

[3] Dove, I. (2014). Analysis of radio propagation inside the human body for in-body localization purposes (Master's thesis, University of Twente).

[4] Parasuraman, R., Kershaw, K., \& Ferre, M. (2013). Experimental investigation of radio signal propagation in scientific facilities for telerobotic applications. International Journal of Advanced Robotic Systems, 10(10), 364 .

[5] Sachdeva, N., \& Sharma, D. (2012). Diversity: A fading reduction technique. International Journal of Advanced Research in Computer Science and Software Engineering, ISSN.

[6] Trenggono, P. P. (2011). Statistical modelling of wind effects on signal propagation for wireless sensor networks (Doctoral dissertation, Queensland University of Technology).

[7] Sim, C. Y. D. (2002). The propagation of VHF and UHF radio waves over sea paths (Doctoral dissertation, University of Leicester)

[8] Píšová, P., \& Chod, J. (2015). Detection of GNSS signals propagation in urban canyos using 3D city models.

[9] Gibson, J. D. (Ed.). (2012). Mobile communications handbook. CRC press.

[10] Appana, D. K., Kumar, C. A., \& Nagappan, N. P. (2009). Channel Estimation in GPRS based Communication System using Bayesian Demodulation.

[11] Miu, A., Tan, G., Balakrishnan, H., \& Apostolopoulos, J. (2004, June). Divert: fine-grained path selection for wireless LANs. In Proceedings of the 2nd international conference on Mobile systems, applications, and services (pp. 203-216). ACM.

[12] Ilcev, S. D. (2011). Surface Reflection and Local Environmental Effects in Maritime and other Mobile
Satellite Communications. International Recent Issues about ECDIS, e-Navigation and Safety at Sea: Marine Navigation and Safety of Sea Transportation, 129.

[13] Zhao, X. (2002). Multipath propagation characterization for terrestrial mobile and fixed microwave communications. Helsinki University of Technology.

[14] Hannah, B. M. (2001). Modelling and simulation of GPS multipath propagation (Doctoral dissertation, Queensland University of Technology).

[15] ITU-R P. 530-17 (2017) ITU-R Recommendation P. 530-17, Propagation data and prediction methods required for the design of terrestrial line-of-sight systems," ITU, Geneva, Switzerland . Available at https://www.itu.int/dms_pubrec/itu-r/rec/p/R-RECP.530-17-201712-I!!PDF-E.pdf. Accessed on November 12,2018

[16] Mukherjee, S., Mukherjee, S., Garg, R. D., Bhardwaj, A., \& Raju, P. L. N. (2013). Evaluation of topographic index in relation to terrain roughness and DEM grid spacing. Journal of earth system science, 122(3), 869-886.

[17] Brubaker, K. M., Myers, W. L., Drohan, P. J., Miller, D. A., \& Boyer, E. W. (2013). The use of LiDAR terrain data in characterizing surface roughness and microtopography. Applied and Environmental Soil Science, 2013.

[18] Deng, Y., Wilson, J. P., \& Bauer, B. O. (2007). DEM resolution dependencies of terrain attributes across a landscape. International Journal of Geographical Information Science, 21(2), 187-213.

[19] Göktaş, P., Altvntaş, A., Topçu, S., \& Karaşan, E. (2014, August). The effect of terrain roughness in the microwave line-of-sight multipath fading estimation based on Rec. ITU-R P. 530-15. In General Assembly and Scientific Symposium (URSI GASS), 2014 XXXIth URSI (pp. 1-4). IEEE. 